\title{
EFECTO ECONÓMICO FINANCIERO DE LOS TRIBUTOS EN LAS EMPRESAS
}

\author{
Eduardo Montes Farro* \\ Alfonso Ugarte Silva** \\ Lourdes Calderón Aguilar*** \\ Juan Miñano Lecaros*****
}

\section{INTRODUCCIÓN}

Es conocida y sufrida por la gran mayoría, la situación económica del país. Hay múltiples razones para que así sea.

Hemos elegido la política tributaria para mostrar cómo se toman decisiones, que perjudican los fines en lugar de beneficiarlos.

Si en la vida personal nos decidimos por ahorrar; todos estarían de acuerdo que hemos tomado una buena decisión. Pero según la forma cómo realicemos el ahorro, obtendremos menores o mejores resultados. Tendríamos en cuenta la regularidad, los montos, los fines para los cuales estamos ahorrando, el beneficio agregado (los intereses) que podemos obtener, etc.

Si acometiéramos, esa sería la palabra, un ahorro de todos nuestros ingresos, no tendríamos para lo elemental. ¿Qué situación tendríamos si persistiéramos en esta forma de ahorrar?

Los tributos en cierta forma es ahorro, cuyos fines deben estar sumamente claros para todos los contribuyentes, y su aplicación debe tener efectos saludables para el país. Lamentablemente, no siempre es así.

Por su importancia, hemos tomado como ejemplo el caso de las empresas, cuyos fines pueden y deben estar en beneficio de la sociedad donde se desenvuelven. Es decir un beneficio mutuo.

El presente trabajo ha contemplado: La revisión de las Leyes, Reglamentos y dispositivos complementarios de los Tributos. Analizar a la empresa como entidad generadora de bienes y servicios, con la finalidad de ser competitivos y poder mantener sus actividades en el tiempo. Examinar las situaciones que se presentan en el aspecto financiero y económico, que surgen por la necesidad de atender las obligaciones tributarias.

\section{CONCEPTO Y PRINCIPIOS DE LOS TRIBUTOS}

\section{Definición y Principios:}

Tributo: Ingreso de derecho público a cuyo pago viene obligado el contribuyente por disponerlo laley.

Vamos a transcribir en forma muy resumida el aporte realizado por el profesor Doctor Luis Bortesi Longhi sobre el particular:

"Tres máximas potestades soberanas puede ejercer el Estado"-decía mi extraordinario

\footnotetext{
* Profesor Asociado y Coordinador de Departamento Académico de la Facultad de Ciencias Contables ** Profesor Asociado y Director de la UPG y del CEUPS de la Facultad de Ciencias Contables

*** Profesora Auxiliar de la Facultad de Ciencias Contables

**** Profesor Auxiliar de la Facultad de Ciencias Contables
} 
catedrático de Derecho Constitucional, el Dr. Raúl Ferrero Reblagiati- "declarar la guerra ( y firmar la paz), imprimir dinero e imponer tributos".

La palabra tributo procede de "Tribu" vasallaje a la etnia conquistada y sometida primero en el aspecto político exigiéndole reconocimiento formal de pleitesía y, como consecuencia, entrega de bienes económicos de carácter pecuniario (ganado por ejemplo) de metales preciosos y luego obligación de pago de dinero.

De los preceptos que amparan la doctrina (o la "filosofía") tributaria moderna, este es el primero: Para ser legítima la imposición debe apoyarse en el consentimiento de la nación por boca de sus representantes y debe por supuesto revestir todos los procedimientos y las formas de una ley.

Este principio que es la LEGALIDAD trae por tierra la usurpación del ejecutivo vía la "delegación de facultades", figura de la cual se usó y abusó en el Perú.

Los otros preceptos de la doctrina tributaria son los siguientes:

\section{Principio de Seguridad Jurídica}

Este principio, que puede considerarse como una prolongación del anterior, contiene dos ideas principales. Primero, que el procedimiento de formación, promulgación y administración tributario sea absolutamente regular. Segundo, que el cuerpo jurídico tributario forme parte de un sistema coherente e integrado, que responda a un criterio de unitariedad y cohesión.

\section{Principio de Uniformidad}

También denominado principio de "igualdad", consiste en asegurar el mismo tratamiento a quienes están en análogas situaciones, con exclusión de todo distingo arbitrario, injusto u hostil contra determinadas personas o frente a categorías de personas ya sean estas naturales o jurídicas. La uniformidad excluye por supuesto también la posibilidad de favorecer a grupos.

\section{Principio de Justicia}

Reconocido en nuestra constitución como de "no confiscatoriedad", significa la garantía de la inviolabilidad de la propiedad.

\section{Principio de Proporcionalidad}

También conocido como de "equidad", supone que la carga mayor debe ser asumida naturalmente por los más ricos y no por los pobres.

\section{Principio de Simplicidad}

Se le llama también de "certeza". Las disposiciones deben ser promulgadas en forma clara, sintética e inequívoca.

\section{Principio de Publicidad}

En el derecho romano reza una máxima categórica: "ley que no se conoce no obliga".

\section{Principio de Economicidad}

La gestión tributaria del gobierno, la gerencia de la SUNAT, tiene un costo administrativo. El estudio, la reglamentación, difusión, administración y recaudación representa un desembolso que debe ser cotejado con el monto que se pretende obtener. Es un principio elemental de las Ciencias Administrativas: el del costo-beneficio.

\section{Principio de Aplicación Eficiente y Eficaz}

Este precepto final es cualitativamente diverso a todos los anteriores y sin ninguna duda es el más importante de todos. El estado agarra (a veces con la verdadera rapacidad de la garra de las aves voraces) una porción de la riqueza nacional determinando el índice que se llama "presión tributaria".

Para justificar la presión tributaria se debería garantizar, cuandomenos, los siguientes resultados. 
1. Correcta administración de la JUSTICIA.

2. Proporcionar SEGURIDAD externa (en las fronteras) e interna (Véase artículo 163 de la Constitución).

3. La prestación gratuita y de alta calidad en los sectores SALUD y EDUCACIÓN. Todos los Tratadistas reconocen que el impuesto debe ser también un mecanismo de justicia social que redistribuye el ingreso nacional aliviando la situación de los estamentos menos favorecidos de la sociedad.

4. Promovery orientar el DESARROLLO.

\section{MARCO LEGAL DE LOS TRIBUTOS}

- Constitución del Estado

- Ley Marco del Sistema Tributario: Código Tributario

- Ley Penal Tributario

- Ley de Exclusión o Reducción de Pena

Estructura de los Tributos:

Gobierno Central

- Impuesto a la Renta

- IGV - ISC

- Derechos Arancelarios

- Régimen Especial del Impuesto a la Renta-RER

- Régimen Único Simplificado

- Impuesto a las acciones del Estado

Gobierno Local

- Predial

- Patrimonio Vehicular

- Juegos de Casino y Máquinas Tragamonedas

Contribuciones Sociales

- Régimen Contributivo de la Seguridad Social en Salud

- Seguro Social Agrario

- Sistema Nacional de Pensiones
- Sistema Privado de Administración de Fondos de Pensiones

- Seguro Complementario de Trabajo de Riesgo

- Seguro de Vida

- Compensación por Tiempo de Servicios- CTS

Otros

- Senati

- Sencico

- Conafovicer

\section{PRESIÓN TRIBUTARIA EMPRE- SARIAL}

Si tomamos el importe de los Ingresos Corrientes Tributarios (en millones de Nuevos soles) del año 2000 , deducido personas naturales, y consideramos el PBI que disponemos por el mismo año; podemos establecer la participación que corresponde a las empresas:

\section{Ingresos Corrientes Tributarios del año 2000 \\ (Deducido Personas Naturales):}

PBI del año 2000: $\quad \frac{20,613}{121,267}=0.16998$

El "impacto" de los Tributos en las empresas en el año 2000 fue de 16,99\% del PBI

El marco legal obliga a las empresas incurrir en una serie de costos que no están orientados a la producción propiamente dicha; sino a satisfacer exigencias que las instituciones estatales nos “delegan" o nos imponen.

Para ilustrar lo que aludimos, seguidamente presentamos algunos casos puntuales:

1. Las siguientes cifras corresponden a la serie de dispositivos emitidos, en el año 2001. 


\section{Resumen de Legislación Tributaria \\ (Enero - Diciembre 2001)}

I. Contribuciones a Essalud y a la ONP 10

II. Beneficios, exoneraciones e inafecciones $\quad 22$

III. Código tributario 25

IV. Impuesto a la renta $\quad 19$

V. Impuesto general a las ventas e impuesto selectivo al consumo $\quad 35$

VI. Impuesto especial a las ventas 1

VII. Impuesto extraordinario de solidaridad 6

VIII. Impuesto a las acciones del estado $\quad 3$

IX. Declaración jurada y pago de tributos 4

$X . \quad$ Declaraciones informativas 4

XI. Normas con incidencia contable $\quad 25$

XII. Impuesto predial $\quad 2$

XIII. Impuesto de alcabala 1

XIV. Impuesto al patrimonio vehicular $\quad \mathbf{2}$

XV. Impuesto a los juegos de casino y máquinas tragamonedas $\quad 7$

XVI. Impuesto a las apuestas 1

XVII. Impuesto a los espectáculos públicos no deportivos 1

XVIII. Impuesto a las embarcaciones de recreo 1

XIX. Aduanas $\quad 34$

Total de dispositivos: en 12 meses 203

Es un total de 203 dispositivos que deben leerse, estudiarse, analizarse, explicar al personal operativo; y aplicarlos rigurosamente.

¿Cuántas personas deben hacerlo? El Asesor Tributario, el Contador, los Asistentes, por lo menos.

¿Qué tiempo se necesita, cuánto ganan estas personas, qué equipos, materiales y energía requieren? ¿Tendrían sobretiempo? Aprovechemos para recordar, que el exceso de horas trabajadas disminuye la calidad del rendimiento del personal. etc.

Las empresas de por sí ya tienen muchos problemas; más aún cuando el mercado es sumamente competitivo.
Dividamos el total de dispositivos entre los 12 meses del año:

$$
\frac{1}{12}=16,91666 \quad \begin{aligned}
& \text { dispositivos } \\
& \text { mensuales }
\end{aligned}
$$

Casi todos los días un nuevo dispositivo.

En una encuesta realizada, los colegas estimaron que fácilmente, en algunos casos, cada dispositivo le demandaba más de 3 horas.

Consideremos una hora como promedio conservador. Prácticamente 17 horas mensuales, como parte de las labores del personal, referidas a la tributación.

Para cuantificar se debe tomar en cuenta el sueldo, más tributos, que se paga a cada 
trabajador que participa en estas labores. Como carga de la empresa tiene una doble significación:

- Pago de remuneraciones y materiales usados.

- No poder contar con personal calificado para las actividades propias de la empresa.

Cabe la pregunta $¿$ Se hace necesario tener más personal, adquirir equipos y suministros, para cubrir esta necesidad tributaria? Muchas veces la respuesta es sí.

2. Conocemos el caso de una empresa que ha tenido la oportunidad de exportar.

Para gestionar la devolución del IGV respectivo, debió informar entre otras cosas, las compras del año anterior.

Ocurre que los comprobantes de pago tienen el RUC de 8 dígitos; y conseguir el RUC de 11 dígitos requeridos se ha convertido en un trabajo de titanes.

También es importante, como efecto financiero, la oportunidad de pago de la obligación tributaria. En el caso del IGV nace la obligación en la fecha de la emisión del comprobante de pago o fecha de entrega del bien, lo que ocurra primero. La mayor parte de veces sin haber percibido el pago correspondiente.

4. Con relación al Impuesto a la Renta se debe abonar mensualmente, como pago a cuenta de presuntas utilidades.

Este conjunto de eventos afecta nrogresivamente la capacidad de maniobra inanciera de las empresas; hasta convertirlas en insolventes.

\section{CONCLUSIONES}

a) La Administración Tributaria es muy compleja innecesariamente. Establece una serie de obligaciones que propician el incumplimiento por parte de los contribuyentes; quienes tienen que elevar sus gastos administrativos y acudir a créditos para atender las demandas tributarias.

b) Es necesario racionalizar la legislación y reglamentos de los tributos, para que se conviertan en una herramienta eficaz de desarrollo del país.

c) Las empresas deben desarrollar sistemas de información que les permita, con el menor costo, determinar sus obligaciones tributarias; $y$, buscar financiamiento que no perturbe su desarrollo empresarial.

\section{BIBLIOGRAFÍA}

Anthony, Robert N. Contabilidad para la Dirección

Código Tributario-D.L. N ${ }^{\circ} 816$

Colección Revista Interlíneas

Chávez Ackermann, Pascual. Impuesto a la Renta

Drucker, Peter F. La Gerencia en tiempos dificiles

Estudio Caballero Bustamante. Manual Tributario 2001

Fernández, I. y Navarro, J.A. ¿Cómo Interpretar un Balance?

Flores Soria, Jaime. Contabilidad Gerencial. Informativo Caballero Bustamante, Revista de Asesoría Especializada - 2000 y 2001

La Página Web de la Sunat

Mornisey, George L. Pensamiento Estratégico. Prentice-Hall Hispanoamericana S.A. Savage, Cristopher I. y John R. Small, Introducción a la Economía Empresarial Sheldon, Oliver. La Filosofía del Management.

Vera Paredes, Isaías y Lourdes Calderón Aguilar, Comentarios al Código Tributario. 